ORIGINAL ARTICLE

\title{
Oral vitamin B12 can change our practice
}

\section{E Nyholm, P Turpin, D Swain, B Cunningham, S Daly, P Nightingale, C Fegan}

\begin{tabular}{|c|c|}
\hline $\begin{array}{l}\text { See end of article for } \\
\text { authors' affiliations }\end{array}$ & Postgrad Med J 2003;79:218-220 \\
\hline $\begin{array}{l}\text { Correspondence to: } \\
\text { Dr Elizabeth S Nyholm, } \\
\text { Yardley Green Medical } \\
\text { Centre, } 73 \text { Yardley Green } \\
\text { Road, Birmingham B9 5PU, } \\
\text { UK; } \\
\text { Liz.nyholm@pc.birminghamha. } \\
\text { wmids.nhs.uk } \\
\text { Submitted } \\
19 \text { October } 2002 \\
\text { Accepted } \\
20 \text { January } 2003\end{array}$ & $\begin{array}{l}\text { Oral vitamin B } 12 \text { can provide an effective alternative to intramuscular injections, so giving patients a } \\
\text { choice and reducing costs in primary care. This study investigated the effectiveness, safety, and } \\
\text { acceptability of oral vitamin B12 as replacement therapy in patients with vitamin B } 12 \text { deficiency in a } \\
\text { city general practice population. Forty patients previously maintained on vitamin B } 12 \text { injections were } \\
\text { given } 1000 \mu g \text { of oral cyanocobalamin daily for up to } 18 \text { months. All the patients maintained satisfac- } \\
\text { tory serum B } 12 \text { levels and showed normal haematology and neurology. Compliance and acceptabil- } \\
\text { ity was excellent. The time for a change in practice has indeed arrived. }\end{array}$ \\
\hline
\end{tabular}

$\mathrm{V}$ tamin B12 is given intramuscularly in the UK despite the fact that oral vitamin B12 in sufficiently large doses is equally effective. Historically, this passive absorption mechanism provided the first treatment for pernicious anaemia. ${ }^{12}$ In the absence of an intact ileum or intrinsic factor, $1.2 \%$ of an oral dose of vitamin B12 will pass across the small bowel. ${ }^{34}$ The dose absorption ratio is remarkably constant in an oral dose range from 1 to $100000 \mu \mathrm{g}$ of hydroxocobalamin and adequate levels of serum vitamin B12 have resulted using oral doses above $500 \mu \mathrm{g}$ daily. ${ }^{5-9}$ Reflecting this, most vitamin B12 replacement therapy is now given orally in Sweden ${ }^{10}{ }^{11}$ and in the USA it is becoming a more popular mode of treatment. Nursing time spent on intramuscular injections is costly-an assessment of the costs of administering injections of vitamin B12 made in 1997 to the 89 patients in our combined inner city practice of 19000 suggested that substantial savings could be made with an oral preparation. ${ }^{12}$ An oral preparation of vitamin B12 (Cytacon 50 $\mu \mathrm{g}$ ) is available in the UK but the NHS licence restricts its use to vitamin B12 deficiency of dietary origin and for vegans.

\section{PATIENTS AND METHODS}

This was a prospective case series of 50 of the 108 eligible patients with vitamin B12 deficiency within the combined practice populations of 19000 patients. Ten patients had pernicious anaemia as confirmed by a positive Schilling test and/or raised intrinsic factor antibody (as confirmed by the autozyme test for anti-intrinsic factor antibody). Nine of the patients had gastrointestinal surgery related vitamin B12 deficiency and the remainder were intrinsic factor negative. Exclusions were because of refusal, cognitive impairment, or acute illness. Patients were recruited to the study at the rate of two or three per week but the study ended on a specific date such that patients took study medication for variable periods of time. There were 17 males and 33 females with an age range of 31 to 90 . Ethical approval was obtained from the East Birmingham Local Research and Ethics Committee. At study entry patients completed a medical history and received a physical examination with emphasis on cognition and the nervous system. Repeat medical histories were taken every six months. Physical examination was repeated in all patients at the end of the study and if the serum vitamin B 12 level fell into the lower $25 \%$ of the reference range (vitamin

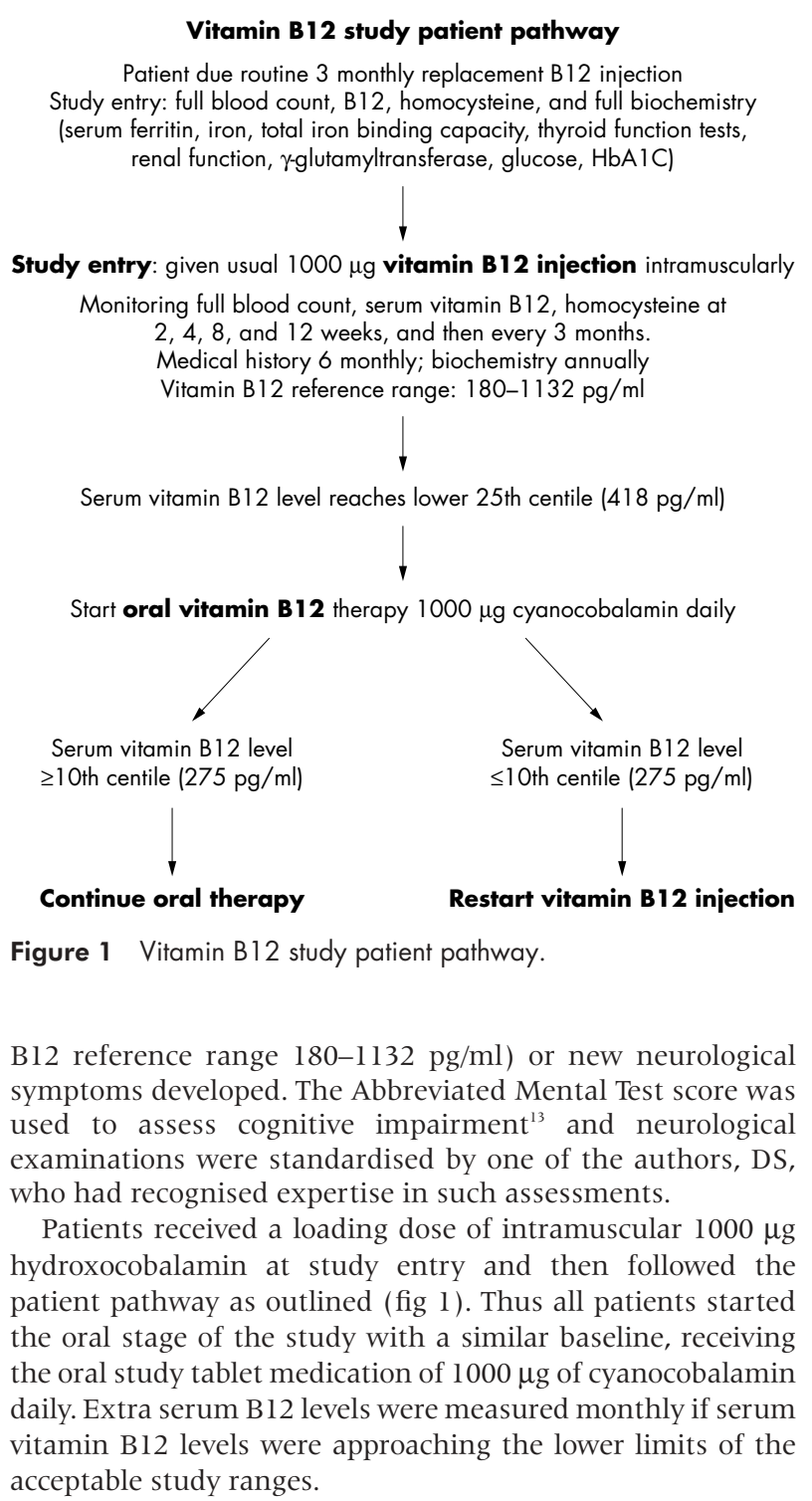

Vitamin B 12 study patient pathway

monthly replacement B12 injection tudy entry: full blood count, B12, homocysteine, and full biochemistry ferritin, iron, total iron binding capacity, thyroid function tests, renal function, $\gamma$-glutamyltransferase, glucose, $\mathrm{HbAlC}$

Study entry: given usual $1000 \mu \mathrm{g}$ vitamin B 12 injection intramuscularly

Monitoring full blood count, serum vitamin B 12, homocysteine a $2,4,8$, and 12 weeks, and then every 3 months. Medical history 6 monthly; biochemistry annually Vitamin B12 reference range: $180-1132 \mathrm{pg} / \mathrm{ml}$

Serum vitamin B12 level reaches lower 25 th centile $(418 \mathrm{pg} / \mathrm{ml})$

Start oral vitamin B 12 therapy $1000 \mu \mathrm{g}$ cyanocobalamin daily

Figure 1 Vitamin B12 study patient pathway.

B12 reference range $180-1132 \mathrm{pg} / \mathrm{ml}$ ) or new neurological symptoms developed. The Abbreviated Mental Test score was used to assess cognitive impairment ${ }^{13}$ and neurological examinations were standardised by one of the authors, DS, who had recognised expertise in such assessments.

Patients received a loading dose of intramuscular $1000 \mu \mathrm{g}$ hydroxocobalamin at study entry and then followed the the oral stage of the study with a similar baseline, receiving the oral study tablet medication of $1000 \mu \mathrm{g}$ of cyanocobalamin daily. Extra serum B12 levels were measured monthly if serum acceptable study ranges. 


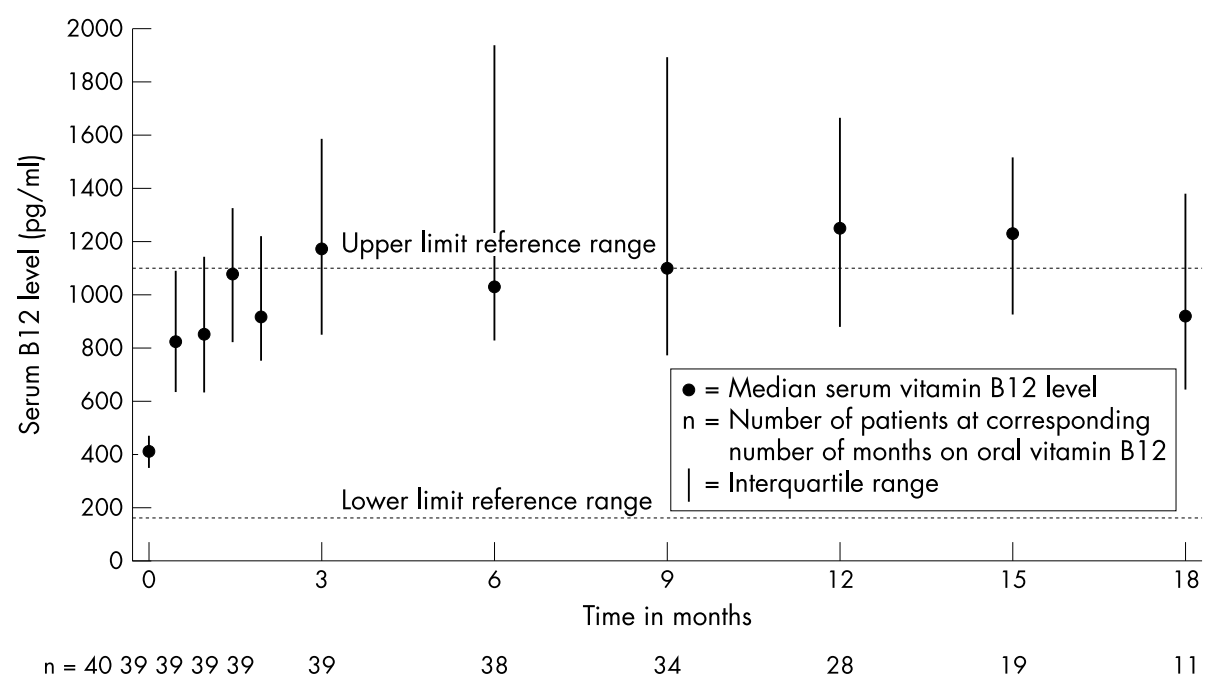

Figure 2 Serum vitamin B 12 levels after oral cyanocobalamin $1000 \mathrm{pg}$ daily.

\begin{tabular}{llllllllll}
\hline \multicolumn{10}{c}{ Months from oral arm entry } \\
\cline { 2 - 10 } & 0 & 1 & 2 & 3 & 6 & 9 & 12 & 15 & 18 \\
\hline Median serum vitamin B12 pg/ml & 410 & 847 & 994 & 1193 & 1060 & 1230 & 1280 & 1273 & 1022 \\
Median homocysteine & 11.5 & 10.1 & 10.6 & 10.3 & 8.9 & 9.4 & 9.1 & 9 & 8 \\
No of patient observations & 34 & 32 & 35 & 33 & 25 & 23 & 20 & 13 & 7 \\
\hline
\end{tabular}

\section{RESULTS}

Of the 50 patients who entered the study and received the intramuscular dose of $1000 \mu \mathrm{g}$ hydroxocobalamin, three patients were withdrawn before starting oral vitamin B12 for social reasons. Two patients whose serum B12 level did not fall sufficiently to reach the lower quartile did not enter the oral phase of the study. Five patients were withdrawn from the oral stage of the study: death (2), protocol violation (2), leaving the area (1). Forty patients were then analysed from the oral treatment group. Patients were recruited to the study at a rate of eight to 10 per month and the study ended on a fixed date over two years later. Thus, patients took the treatments for variable periods of time. Eleven patients took the preparation for 18 months, 19 patients for 15 months, 34 patients took Cytacon for nine months, 38 for six months, and 39 for three months. The values of continuous variables at different time points were compared using Friedman's test (fig 2).

Cyanocobalamin was effective in $100 \%$ of the patients in all the diagnostic groups-that is, no patients had to restart vitamin B12 injections.

There was a plateau in serum vitamin B12 levels at three months on oral treatment with a median value of $1164 \mathrm{pg} / \mathrm{ml}$ (interquartile range $854-1578 \mathrm{pg} / \mathrm{ml}$ ). This compared with a median at the start of oral therapy of $410 \mathrm{pg} / \mathrm{ml}$ (interquartile range $356-473 \mathrm{pg} / \mathrm{ml})$. There is no significant fall in haemoglobin $(\mathrm{p}=0.4)$ or mean corpuscular volume $(\mathrm{p}=$ 0.42 ) over time. Physical examinations undertaken when the serum level of vitamin B12 entered the lower $25 \%$ of the reference range and at the end of the study showed that the treatment did not result in any new neurological complications. Homocysteine levels monitored after the start of oral therapy showed no rise $(p=0.32)$ demonstrating that tissue vitamin B12 deficiency did not occur (table 1). This also provides further evidence that at 18 months of oral treatment there is no indication of impending vitamin B12 deficiency. Most patients $(83 \%)$ preferred the tablet to the injection of vitamin B12,87\% found the tablets highly acceptable treatment, and $13 \%$ said the tablets were acceptable.

\section{Learning points}

- Oral vitamin B12 is effective in the treatment of vitamin B12 deficiency including pernicious anaemia but is rarely used for this indication in the UK.

- The $1000 \mathrm{\mu g}$ tablet of cyanocobalamin used in this study is safe to use for maintenance therapy in UK general practice.

- Patients prefer oral medication to an injection of vitamin B12.

- The burden of work undertaken by community nurses and general practitioners in administering injectable vitamin B12 can be substantially reduced.

- We need to look at our current practice and move forward with oral vitamin B12 replacement therapy.

\section{DISCUSSION}

This study confirms that oral $1000 \mu \mathrm{g}$ cyanocobalamin provides effective maintenance therapy for vitamin B12 deficiency of all causes. General practitioners can be confident that this alternative treatment is both safe and effective in the long term-ongoing monitoring of our patients has substantiated that belief.

An oral treatment can produce substantial savings by removing the necessity for nurse involvement either at home or at the surgery for injection therapy. ${ }^{14}$

Patients much prefer oral medication and given the opportunity to choose between an injection and a tablet of vitamin $\mathrm{B} 12$, clearly demonstrated this preference. Vitamin B12 replacement therapy is ideally suited to a standard monitoring protocol and this should become a regular part of our care.

Patients with the very rare condition of tobacco amblyopia should remain on hydroxocobalamin as there is a theoretical possibility of cyanocobalamin (rather than hydroxocobalamin) increasing the risks of this condition..$^{15}$

There is now an oral alternative ${ }^{4}$ to a parenteral treatment and oral vitamin B12 is now a therapy option. The study confirms oral vitamin $\mathrm{B} 12$ is effective and acceptable as 
maintenance therapy in UK general practice for which we advocate its use. "Medicine's best kept secret" ${ }^{\prime \prime}$ is certainly out and the time for change has arrived.

\section{ACKNOWLEDGEMENTS}

Goldshield Healthcare supported the study by paying for the tablets, salaries to the research nurses, IT, administrative, and pathology costs.

All the authors contributed to the design and the clinical work. EN and PT organised the study. BC and SD ran the study and PN undertook statistical analysis. We are grateful to our colleagues at Yardley Green Medical Centre and to laboratory staff at Birmingham Heartlands Hospital for their help and support in running the study.

\section{Authors' affiliations}

E Nyholm, P Turpin, B Cunningham, S Daly, Yardley Green Medical Centre, Birmingham

D Swain, C Fegan, Consultant Physicians, Birmingham Heartlands Hospital

P Nightingale, Statistician, Wolfson Computer Laboratory, University of Birmingham

\section{REFERENCES}

1 Fraser TR. Bone marrow in the treatment of pernicious anaemia. BM 1894;i: 1172-4

2 Minot GR, Murphy WP. Treatment of pernicious anaemia by a special diet. JAMA 1926;87:470-6.
3 Doscherholmen A, Hagen PS. A dual mechanism of vitamin B 12 plasma absorption J Clin Invest 1957:36:1551-7.

4 Lederle F. Oral cobalamin for pernicious anaemia. Medicine's best kept secret? JAMA 1991;265:94-5.

5 Berlin $H$, Berlin R, Brante $G$. Oral treatment of pernicious anaemia with high doses of vitamin B12 without intrinsic factor. Acta Med Scand 1968; 184:247-58.

6 Mclntyre P A, Hahn R, Masters J M, et al. Treatment of pernicious anaemia with orally administered cyanocobalamin (vitamin B12). Arch Intern Med 1960;106:280-92.

7 Reisner EH, Weiner L, Schittone MT, et al. Oral treatment of pernicious anaemia with vitamin B12 without intrinsic factor. N Engl J Med 1955;253:502-6.

8 Waife SO, Jansen CJ, Crabtree RE, et al. Oral vitamin B 12 without intrinsic factor in the treatment of pernicious anaemia. Ann Intern Med 1963;58:810-17

9 Kuzminski AM, Del Giacco EJ, Allen RH, et al. Effective treatment of cobalamin deficiency with oral cobalamin. Blood 1998:92:1 191-8.

10 Berlin R, Berlin H, Brante $G$, et al. Vitamin B1 2 body stores during oral and parenteral treatment of pernicious anaema. Acta Med Scand 1979,204:81-4.

11 Norberg B. Oral high-dose cyanocobalamin-a contagious concept [editorial]. Rondel 2001;8 (http://www.rondellen.net).

12 Nyholm E. Oral or parenteral therapy for B 12 deficiency [correspondence]. Lancet 1999;353:411.

13 Hodkinson HM. Evaluation of a mental test score for assessment of mental impairment in the elderly. Age Ageing 1972;1:233-8.

14 Walraven C van, Austin P, Naylor D. Vitamin B12 injections versus oral supplements. Can Fam Physician 2001;47:79-86.

15 Freeman AG. Optic neuropathy and chronic cyanide intoxication-a review. J R Soc Med 1988;81:103-6.

\section{IMAGES IN MEDICINE.}

\section{Rice bodies in ischiogluteal bursitis}

A 58 year old woman with rheumatoid arthritis suffered from pain and swelling in the right buttock. The pain was greatly aggravated by sitting. Computed tomography and magnetic resonance imaging (MRI) revealed a cystic mass lesion with thick wall, adjacent to the right ischial tuberosity and gluteus maximus muscle. On T2weighted MRI, the mass contained multiple hypointense small nodules, indicating rice bodies (fig 1). Total resection was performed and histopathological findings were compat- ible with chronic bursitis; rice bodies consisted of dense fibrinous material.

S Yoshida, M Shidoh, K Imai*, A Imai*, Y Konishi**, S Kon**

Department of Radiology, Plastic Surgery*, and Pathology** , Muroran City General Hospital, Yamate-chou 3-8-1, Muroran 051-8512, Japan; mumuh003@swan-bay.ne.jp

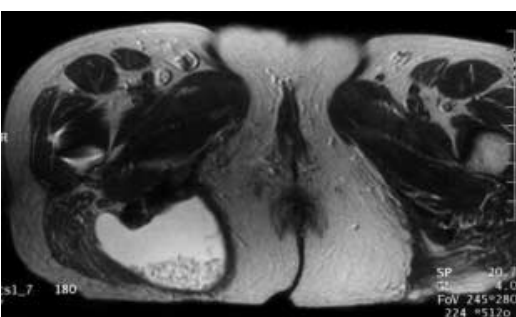

Figure 1 T2-weighted MRI scan. 